\title{
Conflict Within the Boundary of Nature Reserve: The Case of Crocker Range Park in Sabah, Malaysia
}

\author{
Satoshi Watarai ${ }^{a}$
}

\begin{abstract}
For the formation of nature reserves can directly affect the livelihood of indigenous people living in the area, negotiation between the authority and the community is crucial to the management of the natural resources. Crocker Range Park is the largest state park in Sabah state, Malaysia. Since there is a village community living within the boundary of the nature reserve, the state government and the villagers have had a conflict over the land rights. Until the government and the village delegation reached an agreement on the park's management plan in 2015, three actors intervened in the conflict: PACOS Trust, Japan International Cooperation Agency (JICA), and Japan Overseas Cooperation Volunteers (JOCV). In this study, these interventions by different actors were analyzed with the Tripartite Conflict Management (TCM) model. The results indicate that JOCV was the sole actor that was able to communicate with both the state government and the villagers. To support the result, a preliminary research was conducted, and the villagers' perception was investigated through a questionnaire survey. This paper concludes that JOCV was perceived as an actor that can be trusted more than JICA and the state government. This conclusion supports the result of the analysis of TCM model.
\end{abstract}

\section{Keywords}

Information asymmetry, negotiation, nature conservation, Malaysia

Since there is a rich variety of terrestrial biota in forest terrains, it is an essential part of biodiversity conservation to protect forest areas (Lindenmayer, Franklin, and Fischer 2006). Demarcating forest reserves is effective for forest conservation because it is able to protect biota from negative impacts of human activities (Norton 1999). Supported by various actors, such as national governments, NGOs, and international organizations, there has been a significant growth in both the number and area of protected areas (Deguignet et al. 2014).

While expansion of nature reserve is a preferable trend, the formation and operation of forest reserves are challenging tasks for governments. This difficulty is first and foremost manifest in the resentment of local residents living near the reserves who are directly affected by the policies and regulations governing the reserve. For example, there are numerous cases where the locals residing nearby trespass upon nature reserves even after those areas have been officially declared as protected spaces (Hamzah, Ong, and Pampanga 2013). Therefore, it is crucial to analyze the conflict and negotiation over the rights on land and the use of

aThe University of Tokyo, Japan

Correspondent Author:

Satoshi Watarai, Kashiwanoha 5-1-5, Kashiwa, Chiba, Japan 
natural resources within the protected area.

In this paper, Crocker Range Park is assessed and analyzed as a case study of the management of forest reserves. Since there is a village community living within the boundary of the nature reserve, the state government and the villagers have had a conflict over the land rights and the use of natural resources. Until the government and the village delegation reached an agreement on the park's management plan in 2015, three actors tried to intervene in the negotiation to resolve the conflict. The relationships and interactions between the conflicting actors and third-party actors are analyzed respectively using Tripartite Conflict Management (TCM) model, which focuses on the information asymmetry between conflicting actors (Watarai 2015).

To support the results of the analysis, preliminary research, including participant observation and interview, was conducted in the village, the state government of Sabah, and other stakeholders in the negotiation process.

The aim of this paper is to find an effective conflict reconciliation strategy in the management of nature reserve. To this end, this research attempts to explain how and why the conflict between the state government and the villagers was resolved. In order to address the question, the geographical and historical background is described in the chapter 2 . The chapter 3 then shares the analytical model and its results. The chapter 4 explores the villagers' perception with the preliminary research. Finally, conclusions and future work are stated in the chapter 5 .

\section{GEOGRAPHICAL AND HISTORICAL BACKGROUND}

Identified as one of the world's 17 megadiverse countries by Conservation International, Malaysia houses the tropical rainforest of Borneo, which is particularly renowned for its rich biodiversity (Mittermeier 1988). According to the World Wide
Fund for Nature, there are at least 16,036 species of wildlife, 6,100 of which are endemic to Borneo (WWF N.d.).

The state of Sabah located in Borneo has been striving to promote biodiversity conservation. In fact, the first Asia Parks Congress convened by the International Union for Conservation of Nature (IUCN) concluded that collaborative resource management in Sabah was an exemplary model of adaptive management (SDBEC Secretariat 2014).

Out of the number of agencies which work for natural resource management and nature conservation, Sabah Parks is the only governmental body that prohibits any logging activity within its possessive area as a general rule. Sabah Parks owns nine state parks, the total area of which adds up to $3.6 \%$ of the entire state land. Crocker Range Park is the largest of state parks and is renowned for its rich diversity of endemic species.

Located in the southeastern part of Crocker Range Park is the $U$ Village, with a population of approximately 400 people, most of whom are the Murut, the third largest indigenous ethnic group in Sabah state. Murut means "hill people" in their native language, and they are well known as an indigenous ethnic group whose ancestors lived in the mountainous areas in southern part of Sabah. Compared to other indigenous people in the state, Murut people had relatively conserved their native lifestyle until recent years. The villagers in U Village still conserve traditional shifting cultivation of upland rice like as other Murut people in Sabah, whereas other ethnic groups prefer lowland rice because of its efficiency.

The Murut people living in $U$ Village are important in this discussion as the forest reserve instituted within the area covers a large part of the village. The geographical location of Crocker Range Park and U Village is shown in Figure 1.

The present area of Crocker Range Park was first declared as Crocker Range Forest Reserve by 
Department of Forestry in 1969. The nature reserve was demarcated along the mountain range with Mount Kinabalu, one of the highest mountains in Southeast Asia, on its northern end.

Six years after the nature reserve was established, a group of Murut people moved into the area of current U Village. The villagers originally came from Pensiangan, a small town near the border with Indonesia. According to the interview, the first settlers decided to leave their original place due to the difficult access to social services such as education and health care.

In 1984, Crocker Range Forest Reserve was transferred from Department of Forestry to Sabah Parks, a governmental body in charge of the management on nature parks. The nature reserve was initially named "Crocker Range National Park" when it was transferred to Sabah Parks, and it was revised to "Crocker Range Park" in 1996. The parks in Sabah are declared as state parks, despite the fact that they are registered in IUCN as Category II, national parks. Therefore, these parks in Sabah are recognized as national parks from the international point of view.

After the nature reserve was transferred to Sabah Parks, the staffs investigated entire Crocker Range Park and found the village community located within the boundary of the protected area. This was the first occasion which both the state government and the villagers recognized that there was an issue over the land rights.

The conflict between the state government and the villagers was complicated, and the negotiation lasted for more than 30 years. It is possible to assume various reasons for the difficulty of this negotiation process. For example, the complexity of legal land rights over the area constitutes one of the major reasons for complication of the issue. The fact that the jurisdiction of protected area was transferred between different departments of the state government made it difficult to determine which actor possessed the legal right to the land. The villagers moved into the area after the demarcation of the nature reserve but before the establishment of the nature park. Furthermore, Sabah state is very famous for the Native Customary Rights, which legally recognizes the rights of indigenous people on the use of natural resources in their traditional way. These legal environment made the negotiation complicated. It is also possible to consider the difference of ethnicity as a reason of long-lasting conflict, for the majority of government staffs are Kadazan Dusun, the largest indigenous group in Sabah state.

This paper will analyze the function of the third party in the resolution process of this conflict. Generally speaking, it is very difficult to resolve the conflict only by conflicting actors, and mediators play a pivotal role in a conflict settlement (Jandt and Pedersen 1996). In the negotiation process, there are three main third-party actors: PACOS Trust (PACOS), Japan International Cooperation Agency (JICA), and Japan Overseas Cooperation Volunteers (JOCV).

PACOS firstly began a communication with the people in U Village in 2005. PACOS is a local NGO in Sabah, and it is very famous as an advocacy group especially on native land rights. According to the interview to the staffs in PACOS, their strategy is "kasi api dan kasi panas orang kampun", which means "light a fire and heat up villagers". Before PACOS, the villagers could do no more than ignore the order given by the government. However, since PACOS empowered the people to fight against the government, the villagers started to claim their land rights on the area as the Native Customary Rights. Unfortunately, they were not allowed the Native Customary Rights on the land because they originally came from Pensiangan and were not recognized as native people in the protected area.

After the PACOS's attempt resulted in failure, JICA began to address this issue. JICA is a governmental agency in charge of international cooperation through 


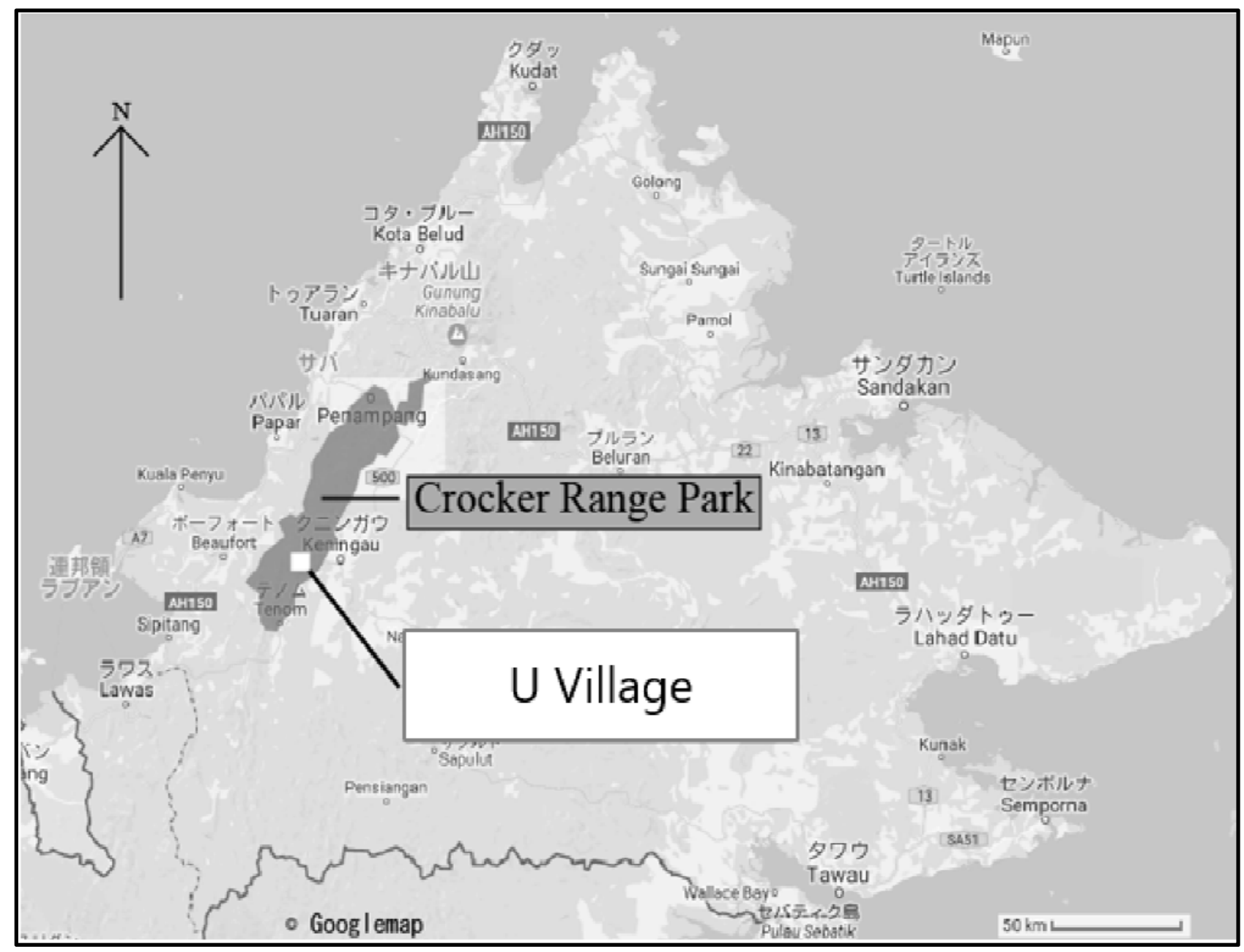

Figure 1. Crocker Range Park and U Village in the Map of Sabah State.

the official development assistance of Japan. JICA started a technical cooperation program on nature conservation with Sabah Parks in 2002. The program, Bornean Biodiversity and Ecosystems Conservation (BBEC) Programme, lasted for 10 years and was taken over by the new program, Sustainable Development for Biodiversity and Ecosystems Conservation in Sabah. In the course of implementation of BBEC, JICA realized the existence of conflict between Crocker Range Park and the local people and decided to include the resolution of the issue in the agenda. JICA began to research on $\mathrm{U}$ Village in 2007 and persuaded Sabah Parks to cooperate with the villagers to protect the natural resources, rather than expelling them from the area, so that JICA and Sabah Parks can operate a community-based management of the nature reserve. However, this attempt resulted in failure, and JICA withdrew from this project site because the task proved to be more difficult than expected to establish a cooperative relationship with the villagers.

Finally, JOCV began their operation in U Village in 2009. JOCV is an international volunteering program offered by the Japanese government. The distinguishing characteristic of JOCV volunteers is the 2-month language training that they undergo with the 
sponsorship of JICA, which equips them with the proficiency to communicate and connect with the locals in their native tongue. Since 2009, JOCV has dispatched a total of seven volunteers to U Village. These volunteers have primarily been engaged in conducting community development programs in the village, as well as collecting data and information for further research into possible avenues to improve the development of the local community.

After the intervention of the three third-party actors, Sabah Parks and U Village finally reached the agreement on the park's management plan in 2015. The main events are shown in Table 1.

\section{TRIPARTITE CONFLICT MANAGEMENT MODEL}

In order to analyze the function of third party in a process of conflict settlement, the Tripartite Conflict Management (TCM) model is effective. Recognizing the limitations of the bipartite conflict management model, Harada (2003) proposed TCM model in the discussion surrounding nature reserve management (Warfield 1993; Pruitt, Kim, and Rubin 2004). In comparison to the bipartite model, the tripartite model presents a more accurate reflection of the actual situation concerning nature conservation in relation to community response. This is due to the considerable extent of involvement by various international organizations that assist developing countries in forming nature reserves.

Figure 2 below illustrates combinations of the nature of relationships among two conflicting actors, $\mathrm{A}$ and $\mathrm{B}$, with a third party, $\mathrm{X}$, in the picture. A solid arrow represents a strong interest, and a dotted arrow represents a weak interest. Statuses (1)-(3) describe instances where the third party has strong interests in both conflicting actors; statuses (4)-(7) exemplify cases where the third party has a strong interest in only one of two conflicting actors. The status (1) is ideally desirable, and the $\mathrm{X}$ in (1) is called neutral third party. Since a neutral third party has strong interests in both conflicting actors, and both conflicting actors also have strong interests in the third party, this breaks the information asymmetry between $\mathrm{A}$ and $\mathrm{B}$, which enables an efficient negotiation.

Through an analysis on the data from the interviews to Sabah Parks and the villagers, this paper indicates the degree of the conflicting actors' interest in the third-party actors.

According to the leader of $U$ Village, the villagers are grateful to PACOS and JOCV: PACOS had lessons on the knowledge of natural resources in forest, the importance of native culture, and the communication skills against authorities; JOCV implemented community development programs especially on income generation, such as homestay program and handicraft program. On the other hand, the leader frankly shared his opinion that JICA's officers rarely came to the village. He said that "they only sit on the chairs in KK (Kota Kinabalu, the capital city of Sabah state)".

While the villagers prefer PACOS and JOCV to JICA, Sabah Parks has a different perception from the villagers. A staff of Sabah Parks stated that JICA and JOCV had cooperated with the state government continuously for decades, whereas PACOS often made issues complicated. In fact, JICA and JOCV have had a variety of programs around the Sabah state, many of which were operated with Sabah Parks. Therefore, Sabah Parks had already built cooperative relationships with JICA and JOCV. On the other hand, since PACOS had a number of law suits with the state government of Sabah, Sabah Parks regarded PACOS as a hostile actor.

These results of the analysis indicate that JOCV volunteers were able to play a role of neutral third party, where the both conflicting actors were strongly interested in JOCV. PACOS could not obtain the interest of Sabah Parks, whereas JICA could not obtain the interest of the villagers. 
Table 1. Chronology of Main Events

\begin{tabular}{ll}
\hline Year & Event \\
\hline 1969 & Crocker Range Forest Reserve was declared \\
1975 & Murut people moved into the protected area \\
1984 & The reserve was transferred to Sabah Parks \\
2005 & PACOS started activities \\
2007 & JICA started research \\
2009 & JOCV started programs \\
2015 & The parks management plan was agreed \\
\hline
\end{tabular}

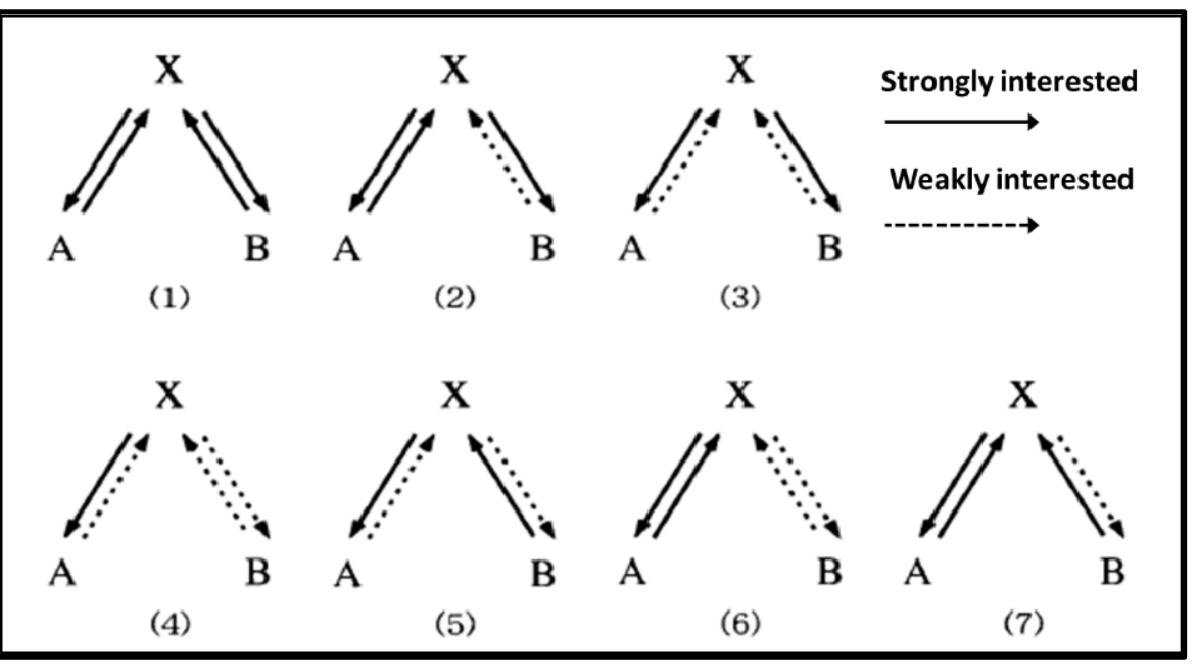

Figure 2. TCM Model.

\section{PRELIMINARY RESEARCH}

In order to support the result of qualitative analysis in the chapter 3 , questionnaire survey was conducted in U Village. In this preliminary research, the villagers' interest in JICA and JOCV, not in PACOS, was investigated.

The survey was written in Malay, and the villagers were asked to assess the state government, the village delegation, JICA, and JOCV using scale 0 to 10 on the following six questions: (1) The closeness of the relationship with the subject; (2) The commitment of the subject to the livelihood improvement of the village; (3) The commitment of the subject to the forest conservation; (4) The commitment of the subject for the development of Sabah state; (5) The degree you feel that the subject is working more for Sabah state or for the village; and (6) The degree you feel that the subject is working more for forest conservation or for the livelihood improvement of the village. The survey was conducted to 14 villagers (seven males, seven females), and the response rate was $100 \%$.

The mean values are calculated respectively, and the sign test was conducted for the difference in the mean values acquired by the four subjects (Sabah state, village delegation, JICA, and JOCV) on each question.

As a result of the sign test, the following results met the significance level of 5\%: (1) The villagers perceive that they are closer to JOCV than to the state 
Table 2. Villagers Perception on 0 to 10 Scale

\begin{tabular}{|c|c|c|c|c|}
\hline Actors & State government & Village delegation & JICA & JOCV \\
\hline Closeness & ${ }^{*} 7.1$ & 7.4 & ${ }^{*} 5.8$ & 8.6 \\
\hline Work for village & 7.1 & 7.6 & 6.5 & 7.9 \\
\hline Work for forest & 8.9 & 8.4 & 7.9 & 8.8 \\
\hline Work for state & 7.6 & 7.6 & 7.3 & 8.4 \\
\hline Work for state $(0)$ or village $(10)$ & ${ }^{*} 6.8$ & 7.7 & ${ }^{*} 6.8$ & 8.7 \\
\hline Work for forest (0) or village (10) & ${ }^{*} 5.7$ & 7.6 & 6.3 & 7.7 \\
\hline
\end{tabular}

Note: ${ }^{*}$ met the significance level of .05, sign test with JOCV.

government or JICA; (2) The villagers perceive that JOCV is working more for the village than for the state compared to the state government or JICA; and (3) The villagers perceive that JOCV is working more for the livelihood improvement of the village than for forest protection compared to the state government. The results are shown in Table 2 .

When the results are applied to the aforementioned model, it is implied that in the perception of the villagers, they had a stronger interest in JOCV than in JICA. This is consistent with the discussion made in the chapter 3 and reinforces its conclusion quantitatively.

\section{CONCLUSIONS}

This paper concludes that JOCV played a pivotal role in the conflict settlement as a neutral third party. Although PACOS and JICA also had large impacts on the negotiation process, they could not function as information-bridges or break asymmetric information, rooting down to the lack of strong interest from conflicting actors.

However, this preliminary study is insufficient in backing up its argument completely. Firstly, there is a statistical limitation in relation to the number of samples, the bias in the population, and the result bias from the operation environment. Moreover, the preliminary study is also limited in that it only demonstrates the villagers' perceived relationship with JOCV and JICA. The study is also expected to demonstrate the head-to-head comparison of the villagers' perception towards JICA and PACOS, that of the state government towards JOCV and PACOS, as well as that of the state government towards JICA and PACOS. This would reinforce the argument that the tripartite relationship among JOCV, the villagers, and the state government was closer to the status (1) in comparison to that of PACOS and the conflicting actors and that of JICA and the conflicting actors. In addition to addressing the above limitations, the further research is also required to analyze the role of JOCV in depth, in order to find the specific qualities which made their intervention possible.

\section{Acknowledgments}

This work is supported by Department of International Studies, Graduate School of Frontier Science, the University of Tokyo. All support is gratefully acknowledged.

\section{References}

Deguignet, M., D. Juffe-Bignoli, J. Harrison, B. MacSharry, N. Burgess, and N. Kingston. 2014. 2014 United Nations List of Protected Areas. Retrieved (https://wdpa.s3.amazonaws. com/WPC2014/2014_UN_LIST_REPORT_EN.pdf).

Hamzah, A., D. J. Ong, and D. Pampanga. 2013. Asian Philosophy of Protected Areas. Retrieved (https://cmsdata. iucn.org/downloads/asian_philosophy_of_protected_area_r 
educed.pdf).

Harada, K. 2003. “A Framework for Conflict Management of Government and Local People Concerning Natural Resources in Protected Areas.” J. For. Econ. 49(2): 35-43.

Jandt, F. and P. Pedersen. 1996. Constructive Conflict Management: Asia-Pacific Cases. Thousand Oaks, CA: Sage Publications.

Lindenmayer, D. B., J. F. Franklin, and J. Fischer. 2006. "General Management Principles and a Checklist of Strategies to Guide Forest Biodiversity Conservation.” Biol. Conserv. 131(3):433-445.

Mittermeier, R. 1988. "Chapter 16 Primate Diversity and the Tropical Forest: Case Studies From Brazil and Madagascar and the Importance of the Megadiversity Countries.” Pp. 145-154 in Biodiversity, edited by O. Wilson and F. Peter. Washinton, D.C.: National Academies Press.

Norton, D. A. 1999. "Forest Reserves." Pp. 525-555 in Maintaining Biodiversity in Forest Ecosystems, edited by M. L. Hunter. Cambridge: Cambridge University Press.

Pruitt, D. G., S. H. Kim, and J. Rubin. 2004. Social Conflict: Escalation, Stalemate, and Settlement. 3rd ed. Boston: McGraw-Hill.

SDBEC Secretariat. 2014. An Innovative Approach Towards a
Society in Harmony With Nature. Kota Kinabalu: Output Digital Print Café.

Warfield, W. 1993. "Public-Policy Conflict Resolution: The Nexus Between Culture and Process.” Pp. 176-193 in Conflict Resolution Theory and Practice: Integration and Application, edited by D. J. D. Sandole and H. Van der Merwe. Manchester: Manchester University Press.

Watarai, S. 2015. "Community Development in the Management Strategy of Nature Reserves: The Case of Sabah Parks.” Presented at the Annual Conference on Management and Social Sciences (ACMASS), September, 2015, Kuala Lumpur, Malaysia.

WWF. N.d. Borneo Wildlife. Retrieved (http://wwf.panda.org/ what_we_do/where_we_work/borneo_forests/about_borneo _forests/borneo_animals/).

\section{Bio}

Satoshi Watarai, Master of Internaitonal Studies, Department of Internaitonal Studies, Graduate School of Frontier Sciences, the University of Tokyo, Japan; research fields: international development, rural development, negotiation, governance, sustainability. 